\title{
Editorials
}

\section{Mental health help-seeking behaviours in young adults}

There is clinical and research consensus that significant cognitive, social, emotional development and adjustment to physical changes occurs during young adulthood, in the period between ages 18 and 24 years. ${ }^{1}$ While three-quarters of psychiatric disorders in adults emerge before the age of 25 years, a European study, comparing access to mental health care by age bands, reported that 18-24-year-old participants were least likely to get care for mental health problems. ${ }^{2}$ In the 2016 UK National Confidential Enquiry into Suicide in Children and Young People, $43 \%$ of people aged $<25$ years who died had no known prior contact with any agencies. ${ }^{3}$ Understanding the risk factors and triggers for mental health problems in young adults is crucial, however we also need to know more about how young adults seek help, if we wish to improve the quality and outcomes of mental health care. Early interventions may improve the prognosis of primary mental health disorders in young adults and reduce the risk of chronicity and progression to more severe secondary disorders, but research-led innovation in mental health care is also hampered by delayed diagnostic assessment and care.

In a recent UK online survey of young adults, $35 \%$ of participants experiencing current emotional or mental health difficulties did not seek any formal or informal help and that perceived stigma, difficulty expressing concerns and accessing help, alongside a preference for self-reliance, were barriers to access to care and support. ${ }^{4} \mathrm{~A}$ systematic review of perceived barriers or facilitators to mental health help-seeking in young people identified 13 'barrier' and 8 'facilitator' key themes. ${ }^{5}$ Since cultural and contextual issues, such as taboos and the structure of service provision, underpin and influence 'help-seeking', the reporting of cross-cultural studies together, was a limitation of the review itself. The most important 'barriers' were 'stigma and embarrassment'; 'poor mental health literacy'; and a preference for 'self-reliance'. There was rather less evidence about 'facilitators', the most important was "positive past experiences with help-seeking', with some evidence relating to 'social support' or 'encouragement from others'; and 'confidentiality and trust in the provider. ${ }^{5}$

However, a challenge to the current conceptual framework may be warranted.
There is a relative lack of discussion in this most recent systematic review and the field in general about how other individuals, other than the young person, mediate access for young adults to mental health care or provide alternative support, nor is the current role of social media and online resources explored.

\section{THE MODEL OF 'HELP-SEEKING BEHAVIOUR'}

Models which see help-seeking as an internal, sequential process within the individual, moving through recognition, expression, identification of sources of help, and subsequent willingness to disclose, may not reflect reality. ${ }^{6}$

With regard to young adults, the role and concerns of family, tutors, peers, and employers are significant. Observed behaviours, such as isolating oneself, eating problems, concerns about image, may be early indicators of psychological distress. Responding to these additional voiced concerns may be challenging for health and social care practitioners, especially at a point where the young adult has capacity to chose to seek help or not: the need to maintain confidentiality and trust is paramount. The proportion of young adults who access mental health care by their own volition and those who access care, facilitated by others, is unknown.

\section{STIGMA}

Salaheddin and Mason, the authors of the UK online survey, ${ }^{4}$ mostly use the term 'mental health' while some survey responders state that their concerns are about 'mental illness'. Word play like this needs to be tackled if stigma is to be faced head on. The field of mental health is in itself far from united in how to conceptualise the area where a common mental health problem becomes diagnosable as a disorder, and which difficulties should best be known as 'mental illness'. Practitioners and researchers need to acknowledge that this lack of clarity may contribute to the difficulties young adults may have, in trying to articulate their concerns and simultaneously avoid attracting a frightening and stigmatising label. Literacy in mental health remains a goal for all, not just young adults.

\section{ASKING FOR HELP}

A UK qualitative study reported negative perceptions by young adults about the value of consulting a GP for mental distress, as participants perceived a GP role to be primarily concerned with physical illness.? Community-based support, for example, through youth services, counselling in tertiary education, and the workplace, may provide more acceptable sources of help for those people who need and prefer non-medicalised approaches, provided risk assessment can be safely undertaken by appropriately skilled practitioners. While $35 \%$ of young adults with mental health problems did not seek help in the recent UK study, $65 \%$ did seek help. ${ }^{4}$ Understanding the differences between help-seekers and non-help-seekers, would be beneficial as research into 'facilitators' is sparse.

\section{SELF-RELIANCE AND INDEPENDENCE}

Total self-reliance is an unrealistic goal for any adult; we are all social beings and in need of support. There is a growing body of evidence relating to the resilience of young people that identifies fundamental building blocks: a secure base, self-esteem from being valued, and being enabled to exercise control in their lives. Young people benefit from patterns of family interaction that are warm, cohesive, and supportive and include belonging to a supportive community. ${ }^{8}$ Reaching out to young people who are more likely to be experiencing mental health difficulties wherever the above factors do not apply or have been lost, for example during transitions, should be a collective societal goal. Primary care practitioners ideally would integrate an understanding of these factors within a holistic consultation framework, routinely and opportunistically asking young adults about mental as well as physical health.

\section{ONLINE MENTAL HEALTH HELP-} SEEKING BEHAVIOUR IN YOUNG ADULTS

Almost all adults aged 16-24 years (91\%) use social networks and the vast majority (90\%) of 16-24-year-olds own a smart phone. ${ }^{8}$ Young people are more likely to use the internet to look up information about mental health issues, with around $33 \%$ of those aged $18-29$ years doing so. ${ }^{9}$ In a recent study $73 \%$ of young people relied on TV, radio, social networks, and websites to get information on self-harm compared to just $11 \%$ who sought information from 


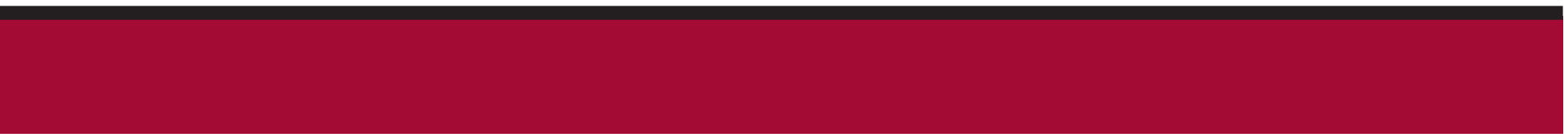

"[Behavioural] models which see help-seeking as an internal, sequential process within the individual, moving through recognition, expression, identification of sources of help, and subsequent willingness to disclose, may not reflect reality.

healthcare professionals. ${ }^{9}$ There is potential for mental health services providers to tap into the support already being provided by online communities and it is likely that as online and mobile services become more integrated with our everyday lives, so too will they become more integrated with the provision of mental health services.

The potential benefits of online mental health help-seeking behaviour include greater anonymity and confidentiality, which lowers concerns regarding any associated stigma. Access 24 hours a day to online resources is easier than face-to-face access to healthcare practitioners and the range of ways in which information is accessed can be empowering to users. ${ }^{10}$ Potential disadvantages to online mental health helpseeking behaviour include cyberbullying: ${ }^{3}$ certain websites can exacerbate mental health problems such as eating disorders and self harm. ${ }^{11}$ A systematic review of 18 studies found that online services did not facilitate offline mental health help-seeking in young people, although the authors noted that young people were satisfied with these services and would recommend them to friends. ${ }^{12}$

While there are some excellent established resources available, overall the recommendation of use of online services should be approached with caution by healthcare practitioners, based on the lack of regulatory control on many websites or community forums. A proposed review of the NHS Apps Library has stalled, which, perhaps, is a tacit acknowledgement of the challenges in regulating the use of online and other mobile health technologies in a rapidly changing field.

\section{IMPLICATIONS FOR PRIMARY HEALTHCARE POLICY AND PRACTICE}

The 2010 No Public Health without Mental Health campaign presents a strong case for collaborative approaches to deliver better preventive and responsive care, especially for children, and young adults, to influence their life course risk and outcomes of mental health problems. ${ }^{8}$ Sources acknowledge the challenges in meeting the needs of young adults in transition from adolescent to adult mental health care and the Royal College of Psychiatrists have summarised approaches to commissioning of services and training of all healthcare practitioners to address the barriers that lead to unmet needs for existing service users as they reach 18 years. Investment in employment, education, housing, social cohesion, sport, and the criminal justice system are seen to be as essential as responsive health services. Actions to address the 'stigma' of mental illness in young adults, especially those mediated by gender and cultural influences, are a priority for a society that promotes mental health and well being for all of its young citizens.

While there is a paucity of research into facilitators, positive past experiences with help-seeking' were the most important across all the literature. Knowledge of the factors influencing the mental health of our patients throughout the life course, our ability to make a contextual assessment of mental health, and diagnose mental illness, put GPs in the ideal position to provide proactive, young person-centred, continuity of care. That is, provided there are an accessible range of complementary primary care and mental health services and also the trustworthy, quality-assured online mental health resources, which young people increasingly turn to, but may in some instances place vulnerable young adults at risk of harm.

\section{Caroline Mitchell,}

GP and Senior Clinical Lecturer, Academic Unit of Primary Medical Care (AUPMC), University of Sheffield, Northern General Hospital, Sheffield.

\section{Brian McMillan,}

NIHR Clinical Lecturer, Centre for Primary

Care, Institute of Population Health, University of Manchester, Manchester.

\section{Teresa Hagan,}

Consultant Clinical Lead Psychologist, Specialist Psychotherapy Service, Sheffield Health and Social Care NHS Foundation Trust, St George's Community Health Centre, Sheffield.

\section{ADDRESS FOR CORRESPONDENCE}

Caroline Mitchell

Academic Unit of Primary Medical Care, University

of Sheffield, Northern General Hospital, Herries

Road, Sheffield S5 7AU, UK.

E-mail: c.mitchellasheffield.ac.uk

\section{Provenance}

Commissioned; not externally peer reviewed.

DOI: 10.3399/bjgp17X688453

\section{REFERENCES}

1. Arnett JJ, Tanner JL, eds. Emerging adults in America: coming of age in the 21st century. Washington, DC: American Psychological Association, 2006.

2. Alonso J, Angermeyer MC, Bernert S, et al. Prevalence of mental disorders in Europe: results from the European Study of the Epidemiology of Mental Disorders (ESEMeD) project. Acta Psychiatr Scand Suppl 2004; (420): 21-27.

3. Suicide by children and young people in England. National Confidential Inquiry into Suicide and Homicide by People with Mental Illness (NCISH). Manchester: University of Manchester, 2016.

4. Salaheddin K, Mason B. Identifying barriers to mental health help-seeking among young adults in the UK: a cross-sectional survey. $\mathrm{Br}$ Gen Pract 2016; DOI: 10.3399/bjgp16X687313.

5. Gulliver A, Griffiths KM, Christensen $\mathrm{H}$. Perceived barriers and facilitators to mental health help-seeking in young people: a systematic review. BMC Psychiatry 2010; 10: 113. doi: 10.1186/1471-244X-10-113.

6. Rickwood D, Deane FP, Wilson CJ, Ciarrochi J. Young people's help-seeking for mental health problems. Australian e-journal for the Advancement of Mental Health 2005; 4(3): 8.

7. Biddle L, Donovan JL, Gunnell D, Sharp D. Young adults' perceptions of GPs as a help source for mental distress: a qualitative study. Br J Gen Pract 2006; 56(533): 924-931.

8. Royal College of Psychiatrists. No health without public mental health: the case for action. Position Statement PS4/2010. 2010. http://www.rcpsych.ac.uk/pdf/Position\%20 Statement $\% 204 \% 20$ website.pdf laccessed 2 Dec 2016).

9. Ofcom. The UK is now a smartphone society. 2015. http://media.ofcom.org.uk/news/2015/ cmr-uk-2015/ laccessed 2 Dec 2016).

10. Reach Out. Help seeking online. http:// au.professionals.reachout.com/help-seekingonline (accessed 2 Dec 2016)

11. Cello Group. Talking self harm. 2012. http:// unw.cellogroup.com/pdfs/talking_self_harm pdf laccessed 2 Dec 2016).

12. Gowen LK. Online mental health information seeking in young adults with mental health challenges. Journal of Technology in Human Services 2013; 31(2): 97-111. 